University of Nebraska - Lincoln

DigitalCommons@University of Nebraska - Lincoln

Agronomy \& Horticulture - Faculty Publications

Agronomy and Horticulture Department

2013

Mapping soybean aphid resistance genes in PI 567598B

\author{
Carmille Bales \\ Michigan State University \\ Guorong Zhang \\ Michigan State University \\ Menghan Liu \\ Michigan State University \\ Clarice Mensah \\ Monsanto Company, Huxley, IA \\ Cuihua Gu \\ Michigan State University
}

See next page for additional authors

Follow this and additional works at: https://digitalcommons.unl.edu/agronomyfacpub

Part of the Agricultural Science Commons, Agriculture Commons, Agronomy and Crop Sciences Commons, Botany Commons, Horticulture Commons, Other Plant Sciences Commons, and the Plant Biology Commons

Bales, Carmille; Zhang, Guorong; Liu, Menghan; Mensah, Clarice; Gu, Cuihua; Song, Qijian; Hyten, D. L.; Cregan, P. B.; and Wang, Dechun, "Mapping soybean aphid resistance genes in PI 567598B" (2013). Agronomy \& Horticulture -- Faculty Publications. 810.

https://digitalcommons.unl.edu/agronomyfacpub/810

This Article is brought to you for free and open access by the Agronomy and Horticulture Department at DigitalCommons@University of Nebraska - Lincoln. It has been accepted for inclusion in Agronomy \& Horticulture -Faculty Publications by an authorized administrator of DigitalCommons@University of Nebraska - Lincoln. 


\section{Authors}

Carmille Bales, Guorong Zhang, Menghan Liu, Clarice Mensah, Cuihua Gu, Qijian Song, D. L. Hyten, P. B. Cregan, and Dechun Wang 


\title{
Mapping soybean aphid resistance genes in PI 567598B
}

\author{
Carmille Bales · Guorong Zhang • Menghan Liu \\ Clarice Mensah • Cuihua Gu • Qijian Song • \\ David Hyten $\cdot$ Perry Cregan $\cdot$ Dechun Wang
}

Received: 7 November 2012/ Accepted: 8 May 2013/Published online: 21 May 2013

(C) Springer-Verlag Berlin Heidelberg 2013

\begin{abstract}
The soybean aphid (Aphis glycines Matsumura) has been a major pest of soybean [Glycine max (L.) Merr.] in North America since it was first reported in 2000. Our previous study revealed that the strong aphid resistance of plant introduction (PI) 567598B was controlled by two recessive genes. The objective of this study was to locate these two genes on the soybean genetic linkage map using molecular markers. A mapping population of $282 \mathrm{~F}_{4: 5}$ lines derived from IA2070 $\times$ E06902 was evaluated for aphid resistance in a field trial in 2009 and a greenhouse trial in 2010. Two quantitative trait loci (QTLs) were identified using the composite and multiple interval mapping methods, and were mapped on chromosomes 7 (linkage group M) and 16 (linkage group J), respectively. E06902, a parent derived from PI 567598B, conferred resistance at both loci. In the 2010 greenhouse trial, each of the two QTLs explained over $30 \%$ of the phenotypic variation. Significant epistatic interaction was also found between these two QTLs. However, in the 2009 field trial, only the QTL on
\end{abstract}

Communicated by I. Rajcan.

C. Bales · G. Zhang $\cdot$ M. Liu $\cdot$ C. Gu $\cdot$ D. Wang $(\bowtie)$ Department of Plant, Soil and Microbial Sciences, Michigan

State University, East Lansing, MI 48824, USA

e-mail:wangdech@msu.edu

G. Zhang

Agricultural Research Center-Hays, Kansas State University, Hays, KS 67601, USA

C. Mensah

Monsanto Company, 1551 Highway 210, Huxley, IA 50124, USA

Q. Song · D. Hyten · P. Cregan

USDA-ARS, Soybean Genomic Laboratory, Beltsville, MD, USA chromosome 16 was found and it explained $56.1 \%$ of the phenotypic variation. These two QTLs and their interaction were confirmed with another population consisting of 94 $\mathrm{F}_{2: 5}$ lines in the 2008 and 2009 greenhouse trials. For both trials in the alternative population, these two loci explained about 50 and $80.4 \%$ of the total phenotypic variation, respectively. Our study shows that soybean aphid isolate used in the 2009 field trial defeated the QTL found on chromosome 7. Presence of the QTL on chromosome 16 conferred soybean aphid resistance in all trials. The markers linked to the aphid-resistant QTLs in PI 567598B or its derived lines can be used in marker-assisted breeding for aphid resistance.

\section{Introduction}

The soybean aphid is one of the most damaging pests on soybean. It can reduce yield either by feeding directly on soybean or transmitting various viruses (Wu et al. 2004); such loss can reach up to $88 \%$. Soybean aphids can also affect seed quality by reducing the oil content (Beckendorf et al. 2008).

Host resistance is considered an effective, economical, and environmentally friendly means for pest control. There are two types of host resistance to insects: antibiosis and antixenosis (Painter 1951). Antibiosis affects insect biology and reduces insect populations. Antixenosis affects insect behavior and is expressed as non-preference for certain plants. Researchers in the US have identified several aphidresistant germplasm accessions (Hill et al. 2004; Mensah et al. 2005; Diaz-Montano et al. 2006; Hesler et al. 2007; Hesler and Dashiell 2008; Mian et al. 2008a). Genetic studies have shown that the antibiosis resistance in Dowling and Jackson were both controlled by a single dominant gene (Hill 
et al. 2006a, b). The gene in Dowling was named Rag1 (Hill et al. 2006a). Later, Ragl and the resistance gene (Rag) in Jackson were both mapped in the same genomic region on chromosome 7 [linkage group (LG) M] (Li et al. 2007). Similarly, a single dominant gene, $\operatorname{Rag} 2$, controlled antibiosis resistance in PI 243540 (Kang et al. 2008) was mapped on chromosome 13 (LG F) (Mian et al. 2008b). A single dominant gene controlling the antibiosis resistance in PI 200538 was mapped in the same genomic region as Rag2 (Hill et al. 2009). A codominant gene, Rag3, on chromosome 16 (LG J) controls the antixenosis resistance in PI 567543C (Zhang et al. 2010). However, the antibiosis resistance in both PI 567541B and PI 567598B is controlled by two recessive genes (Mensah et al. 2008). A genetic mapping study located the two genes in PI 567541B on chromosomes 7 and 13 (LG M and F) (Zhang et al. 2009). The gene on chromosome 7 (LG M) was mapped in the same genomic region as Ragl and was later designated rag1_c. The gene on chromosome 13 (LG F) was located far from Rag2 and was later designated rag4 (Zhang et al. 2009). Significant epistatic interaction was also found between the two genes identified in PI 567541B (Zhang et al. 2009).

Dominant and recessive genes were found to control aphid resistance in other crops such as cowpea, barley, peach, wheat, corn and peanut. The aphid (Aphis craccivora Koch) resistance in cowpea (Vigna unguiculata L.) involves a single dominant gene (Pathak 1988). The aphid resistance in spring barley (Hordeum vulgare L.) is controlled by two dominant genes (Mornhinweg et al. 2002). In the peach cultivar 'Rubira', the resistance to the green peach aphid (Myzus persicae) is controlled by a single dominant gene (Pascal et al. 2002). In wheat (Triticum spp.), eight independent dominant genes each confer resistance to the Russian wheat aphid (Diuraphis noxia) from different resistance sources (Liu et al. 2005), while one recessive gene contributes to the resistance in Triticum tauschii line SQ24 (Nkongolo et al. 1991). A single recessive gene was also found to control resistance to corn leaf aphid (Rhopalosiphum maidis Fitch) (So et al. 2010) and the groundnut rosette disease vector, Aphis craccivora, infesting peanut (Herselman et al. 2004).

Commercial varieties with Ragl have been available in the US. However, at least three biotypes of soybean aphid have been identified and Ragl is only effective against biotype 1 (Kim et al. 2008, Hill et al. 2010). The soybean aphid in Michigan might be another biotype, since it overcame both Rag1 and Rag2 (unpublished data). Using microsatellite markers, Michel et al. (2009) found that the population genetic structure of soybean aphids in Michigan differed from those collected from the other eight states. Therefore, finding new sources of resistance and new resistance genes is necessary to control the newly discovered or evolved biotypes. PI 567598B and its derived lines have strong antibiosis resistance (Mensah et al. 2005) and resistance to soybean aphids as shown by biotype studies conducted in several states (Cooper 2012; Mian et al. 2008a). However, little is known about the genomic locations of the two recessive genes for the aphid resistance in PI 567598B; this could hinder its utilization. Quantitative trait loci (QTL) analysis is a powerful tool to explore the genetic mechanisms, since it not only identifies the loci, but also determines their effects. The objective of this study was to map the aphid resistance loci in PI 567598B with molecular markers.

\section{Materials and methods}

QTL mapping

\section{Plant materials}

A population with $282 \mathrm{~F}_{4: 5}$ recombinant inbred lines (RILs) was developed from a cross between E06902 and IA2070 through the single seed descent method and used for the mapping study. E06902 is an elite advanced breeding line derived from Titan x PI 567598B and possesses aphid resistance similar to that of PI 567598B in field evaluations (unpublished data). Titan (Diers et al. 1999) is susceptible to soybean aphids. IA2070 is an experimental line from Iowa State University and is susceptible to soybean aphids.

\section{Aphid resistance evaluation}

The $\mathrm{F}_{4: 5}$ RILs, parent, and the grandparent PI 567598B were evaluated for aphid damage without replication in the field in the summer of 2009. Evaluation was carried out in a $12.2 \times 18.3 \mathrm{~m}$ aphid- and predator-proof cage (Redwood Empire Awning Co., Santa Rosa, CA, USA) on the Agronomy Farm at Michigan State University (MSU). Each line was planted in a single-row plot, $60 \mathrm{~cm}$ long with a row spacing of $60 \mathrm{~cm}$. The average number of plants per plot was more than 10 with most lines having 12 plants.

Greenhouse evaluations were conducted for the mapping population $\left(\mathrm{F}_{4: 6}\right.$ lines) in the fall of 2010 without replication, while the parental lines and PI 567598B were replicated three times. Eight seeds per line were planted in a large plastic pot $105 \mathrm{~mm}$ in diameter and $125 \mathrm{~mm}$ deep. The greenhouse was maintained at $26 / 15^{\circ} \mathrm{C}$ day/night temperature and sodium vapor lights were used to supplement light intensity during the day (14 h).

In both field and greenhouse trials, each plant was inoculated at the V2 stage with two wingless soybean aphids. All aphid resistance evaluation trials were choice tests, which identified resistance genotypes with either antibiosis or antixenosis resistance. The aphids used for infestation in the field trial were collected from a naturally infested field on the 
MSU Agronomy Farm during the summer of 2009. The aphids used in the greenhouse infestation in the fall of 2010 were from greenhouse-maintained aphids originally collected from a naturally infested field on the MSU Agronomy Farm in the summer of 2010.

Aphid resistance was visually rated for each plant 3 weeks after infestation in the summer 2009 test and 3 and 4 weeks after infestation in the fall 2010 test, using a scale of 0-4 developed by Mensah et al. (2005, 2008). The following criteria were used: $0=$ no aphids; $0.5=$ less than 10 aphids per plant, no colony formed; $1=11-100$ aphids per plant, plant appears healthy; $1.5=101-150$ aphids per plant, plant appears healthy; $2=151-300$ aphids per plant, mostly on the young leaves or tender stems, plant appears healthy; $2.5=301-500$ aphids per plant, plant appears healthy; $3=501-800$ aphids per plant, young leaves and tender stems covered with aphids, leaves slightly curly and shiny; $3.5=$ More than 800 aphids per plant, plants stunted, leaves curled and slightly yellow, no sooty mold and few cast skins; $4=$ more than 800 aphids per plant, plant stunted, leaves severely curled and yellow, covered with sooty mold and cast skins.

A damage index (DI) for each line was calculated by the following formula (Mensah et al. 2005): DI $=\sum($ Scale value $\times$ No. of plants in the category $) /(4 \times$ Total no. of plants $) \times 100$. The DI ranges between 0 for no infestation and 100 for the most severe damage. The DI was used as an indicator of aphid resistance and was applied in the following analyses.

\section{DNA extraction and marker analysis}

Before infestation, the non-expanded trifoliate leaves from each line were bulk harvested for genomic DNA isolation. The DNA was extracted with the CTAB (hexadecyltrimethylammonium bromide) method as described by Kisha et al. (1997), and the concentration was determined with a ND-1000 Spectrophotometer (NanoDrop Technologies, Inc., Wilmington, DE, USA). Simple sequence repeat (SSR) markers (Song et al. 2004) were used to amplify the genomic DNA according to the PCR protocol described by Cregan and Quigley (1997), using a MJ Tetrad ${ }^{\mathrm{TM}}$ thermal cycler (MJ Research, Waltham, MA). PCR products were detected on $6 \%$ non-denaturing polyacrylamide gels using a DASG-400-50 electrophoresis system (C.B.S. Scientific Co., Del Mar, CA, USA) as described by Wang et al. (2003). Gels stained with ethidium bromide were photographed, and scored under UV light.

To accelerate the location of the loci associated with the aphid resistance, the bulked segregant analysis method described by Michelmore et al. (1991) was used. Based on the 2010 phenotypic data, 10 resistant lines with the lowest DI values and 10 susceptible lines with the highest DI values were selected to form a resistant pool and a susceptible pool, respectively. Parental polymorphic SSR markers at approximately every $15 \mathrm{cM}$ of the integrated soybean map of Song et al. (2004) were selected to test the polymorphism between the two bulked DNA pools. The polymorphic markers between the two pools were chosen to genotype the individual lines in the two pools together with the two parents. The markers that appeared to be associated with the aphid resistance were genotyped on the remaining lines of the whole mapping population. The genomic regions associated with the aphid resistance were then saturated with additional markers. Additional SSR markers within the candidate region were selected from 33,065 BARCSOYSSR_1.0 database (Song et al. 2010) and were screened. Primers and hybridization probes for single nucleotide polymorphic (SNP) markers were developed for TaqMan ${ }^{\circledR}$ endpoint genotyping assay (Life Technologies, Carlsbad, CA, USA) performed using Lightcycler $^{\circledR} 480$ (Roche Applied Science, Indianapolis, IN, USA). The SNP markers were selected from the SoySNP50K genotyping array for Illumina Infinium II assay (Song et al. 2013). Flanking sequences were extracted based on the genomic physical position from the soybean whole genome sequence assembly, Glyma v1.0 (www. phytozome.net/soybean).

\section{Statistical and QTL analysis}

Pearson correlation for the aphid resistance between trials was calculated using $\mathrm{R}$ statistical software (R Development Core Team 2008). A linkage map was constructed with the Kosambi function and a LOD score of 3 using JoinMap 4.0 (Van Ooijen 2006). Then, linkage groups were assigned to specific chromosomes according to the soybean consensus map (Song et al. 2004). The maps and QTL intervals were drawn using MapChart (Voorrips 2002). Composite interval mapping (CIM) was performed to locate the aphid resistance QTLs using QTL Cartographer V2.5 with the standard model Zmapqtl 6 (Wang et al. 2008). The CIM analysis uses markers other than the interval being tested as cofactors to control the genetic background (Zeng 1994). The forward and backward regression method was used to select markers as cofactors. The walking speed chosen for CIM was $1 \mathrm{cM}$. The empirical LOD threshold at $5 \%$ probability level was determined by a 1,000-permutation test (Churchill and Doerge 1994). The QTL $\times$ QTL interaction was further determined using the multiple interval mapping (MIM) method of QTL Cartographer.

Alternative population

A population of $94 \mathrm{~F}_{2}$-derived lines was developed from a cross of PI $567598 \mathrm{~B} \times$ Titan and was used as an 
alternative population to confirm the presence of the QTLs found from the mapping population.

Two greenhouse trials were conducted for aphid resistance evaluation in the greenhouse on the MSU campus in 2008 and 2009 using the same procedure as described for the mapping population. Six seeds per line were planted in small plastic pots. The same aphid infestation and damage rating methods were used as described for the mapping population, but the aphids used for infestation were from a clone collected and maintained from the naturally infested field on the MSU Agronomy Farm in 2002. DNA extraction, genotyping, and QTL analysis were conducted as described for the mapping population; but only polymorphic SSR markers were genotyped for this alternative population.

\section{Results}

Phenotypic analysis

The phenotypic values of the $282 \mathrm{~F}_{4}$-derived RILs and its parents, and the resistant source PI 567598B are summarized in Table 1. In both field and greenhouse trials, the susceptible parent, IA2070, was severely damaged by the aphids, while the resistant parent E06902 and PI 567598B were not. There was no significant difference in aphid resistance between E06902 and PI 567598B. Correlation between the 3- and 4-week ratings from the 2010 greenhouse trial was strong $(r=0.88, P<0.0001)$. However, ratings from the 2010 greenhouse trial were not strongly correlated with the 2009 field ratings $(0.37$ and 0.44 for the week 3 and 4 ratings, respectively, $P<0.0001)$. The distributions for the population ratings in both field and greenhouse trials were continuous, but not normal ( $W=0.80,0.92$ and 0.92 , respectively at $P<0.0001$ ), and the distribution in the field trial appeared bimodal (Fig. 1a, $\mathrm{b}, \mathrm{c})$. This indicates that a limited number of major genes might control the aphid resistance in PI 567598B.
QTL analysis

Among 1056 SSR markers, 38 revealed polymorphism between the resistant and the susceptible bulk DNA samples. These 38 markers were from chromosomes 1, 3, 7, 13, 16 and 18 (LGs D1a, N, M, F, J and G). Only Satt654 and Sct_001 on chromosome 16 (LG J) and Satt435 on chromosome 7 (LG M) appeared to be associated with aphid resistance when the individual lines from the DNA pools were genotyped. Therefore, these two regions were saturated with parental polymorphic markers within $\pm 20 \mathrm{cM}$ in the consensus map (Song et al. 2004) using the whole population. Based on the markers from BARCSOYSSR 1.0 database (Song et al. 2010), 48 additional markers were screened for polymorphism within the identified intervals. BARCSOYSSR16_0366 on chromosome 16 was found to be associated with aphid resistance, while four other markers between Satt 435 and Satt323 in the chromosome 7 interval were found to be polymorphic. SNP markers in these two chromosome intervals were also extracted from the SNP list in SoySNP50K genotyping array (Song et al. 2013) and designed for TaqMan ${ }^{\circledR}$ endpoint genotyping assay.

A total of eight SSR and four SNP markers were mapped to the interval on chromosome 16, spanning a total of $43.5 \mathrm{cM}$ (Fig. 2a); while seven SSR and one SNP marker were mapped to the interval on chromosome 7 , spanning a total of $45.9 \mathrm{cM}$ (Fig. 2d).

The QTL analysis detected two QTLs based on the greenhouse trial, while only the one on chromosome 16 was significant in the field trial. In both trials, the allele from E06902 conferred resistance against soybean aphids at the identified QTLs. Using the CIM method, the QTL on chromosome 16 was consistently mapped between Gm16_6262227_C_T and Gm16_6424067_A_G and explained $30.7-45.8 \%$ of the phenotypic variation, with the field trial having the highest percentage (Table 2; Fig. 2a). The QTL on chromosome 7 was only detected in the greenhouse trials and located between Satt435 and

Table 1 Mean damage index of the $\mathrm{F}_{4}$-derived main mapping population and its parental lines and grandparent, PI 567598B, in the field trial in summer 2009 and greenhouse trial in fall 2010

\begin{tabular}{|c|c|c|c|c|c|c|}
\hline \multirow[t]{2}{*}{ Trial } & \multicolumn{2}{|l|}{ Parents $^{\mathrm{a}}$} & \multirow{2}{*}{$\begin{array}{l}\text { Grandparent }{ }^{\mathrm{a}} \\
\text { PI 567598B }\end{array}$} & \multicolumn{3}{|c|}{$\mathrm{F}_{4}$-derived lines } \\
\hline & IA2070 & E06902 & & Mean & Range & $\mathrm{SE}$ \\
\hline \multicolumn{7}{|l|}{ Field 2009} \\
\hline 3-week rating & $87.5 b$ & $16.8 \mathrm{a}$ & $12.5 \mathrm{a}$ & 57.0 & $12.5 \sim 87.5$ & 24.0 \\
\hline \multicolumn{7}{|l|}{ Greenhouse 2010} \\
\hline 3-week rating & $85.5 b$ & $19.0 \mathrm{a}$ & $16.3 \mathrm{a}$ & 46.5 & $12.5 \sim 87.5$ & 23.3 \\
\hline 4-week rating & $87.5 b$ & $15.5 \mathrm{a}$ & $23.3 \mathrm{a}$ & 46.8 & $12.5 \sim 97.5$ & 30.5 \\
\hline
\end{tabular}

${ }^{a}$ Within trials and ratings, means followed by the same letters are not significantly different according to Fisher's Protected LSD $(P=0.05)$ 

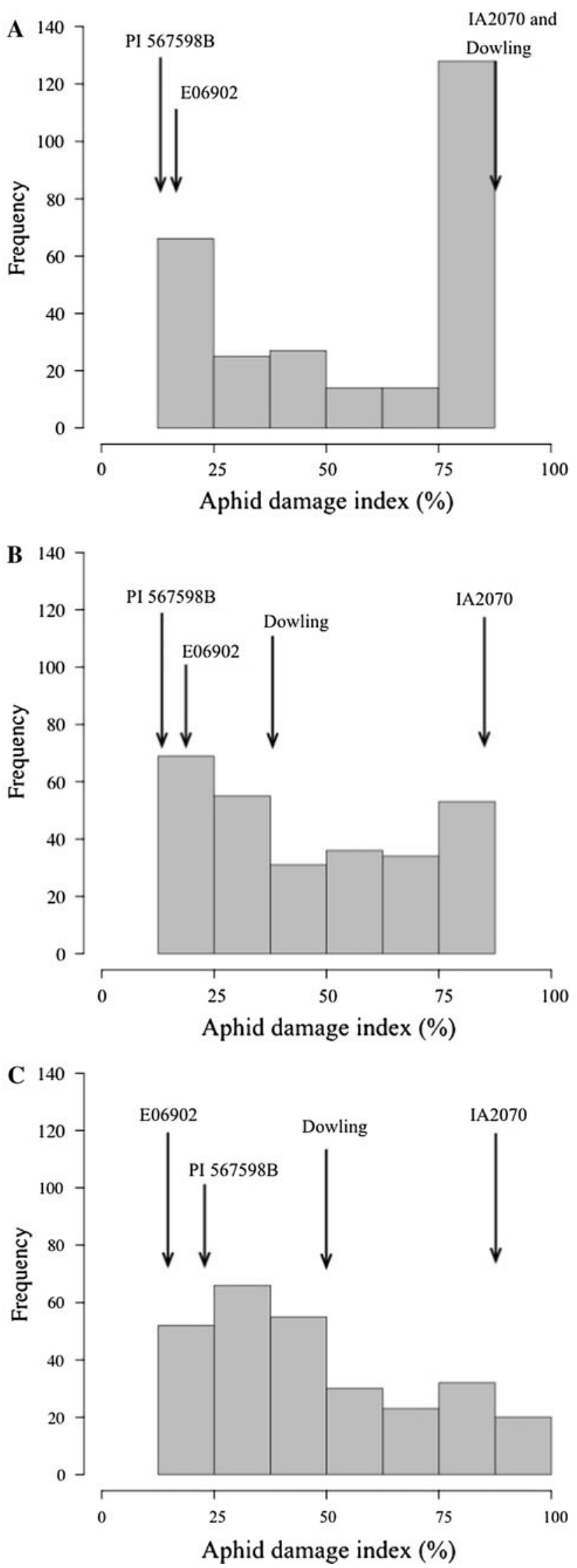

Fig. 1 Frequency distribution of soybean aphid damage index (\%) taken from $\mathrm{F}_{4}$-derived lines of the cross IA2070 $\times$ E06902. Parental lines, PI 567598B, and Dowling ratings are shown by arrows. a Three-week rating in the field trial in summer 2009, b 3-week rating in the greenhouse trial in fall 2010, $\mathbf{c} 4$-week rating in the greenhouse trial in fall 2010

BARCSOYSSR_07_0309, explaining over $30 \%$ of the phenotypic variation (Table 2; Fig. 2d).

The MIM method was further conducted to determine whether there was significant QTL interaction. The MIM method detected the same QTLs as CIM method with two QTLs in the greenhouse trial and one QTL in the field trial (Table 4). For the week 4 ratings in the greenhouse trial, MIM method detected a significant additive $\times$ additive interaction between the two QTLs located on chromosome 7 and 16, but this was not the case for the week 3 ratings. The LOD score of the QTL interaction is 3.4 and explained $1.2 \%$ of the total phenotypic variations. The two QTLs together with their interaction explained $41.7 \%$ of the total phenotypic variation. For the week 3 ratings, these two QTLs together explained $33.6 \%$ of the phenotypic variation. The QTL on chromosome 16 detected in the field trial explained the highest phenotypic variation, $56.1 \%$.

\section{QTL confirmation}

For the alternative population, a dense aphid population developed on the susceptible parent Titan while resistant parent PI 567598B had very few aphids in both 2008 and 2009 trials (Table 3). A total of four markers on chromosome 7 and four markers on chromosome 16 were genotyped. The marker orders were highly comparable with those in the consensus map (Song et al. 2004).

With the CIM method, one QTL was detected on each linkage group in both trials (Fig. 2c, f). The QTLs were located in similar regions between trials. The QTL on chromosome 7 was located between Satt567 and Satt435, explaining about 15 and $20 \%$ of the total phenotypic variation in the 2008 and 2009 trials, respectively (Table 2). The QTL on chromosome 16 was located between Satt 285 and Satt 414 and explained about 30 and $40 \%$ of the total phenotypic variation in the 2008 and 2009 trials, respectively. The PI 567598B allele at both loci conferred resistance.

The two QTLs identified with the CIM method were also found using the MIM method in each trial (Table 4). No QTL interactions were found in the 2008 trial. However, a significant additive $\times$ additive interaction between the two QTLs was detected in the 2009 trial. The LOD score of the QTL interaction was 6.0 and it explained $9.2 \%$ of the total phenotypic variation. The two QTLs 
Fig. 2 Locations of soybean aphid resistance QTLs using composite interval mapping method. Solid bars represent QTLs for the three-week rating in the 2009 field trial (2009Field-Wk3). Diagonally hatched bars represent QTLs for the 3-week rating in the 2010 trial (2010GH-Wk3). Open bars represent QTLs for the 4-week rating in the 2010 trial (2010GH-Wk4) a and d Maps of chromosome 16 (LG J) and 7 (LG M) in the mapping population, the QTL positions are listed at its left side; $\mathbf{b}$ and e Consensus maps of chromosome 16 (LG J) and 7 (LG M) (Song et al. 2004); c and $\mathbf{f}$ Maps of chromosome 16 (LG J) and 7 (LG M) in the alternative population, the QTL positions are listed at its right side
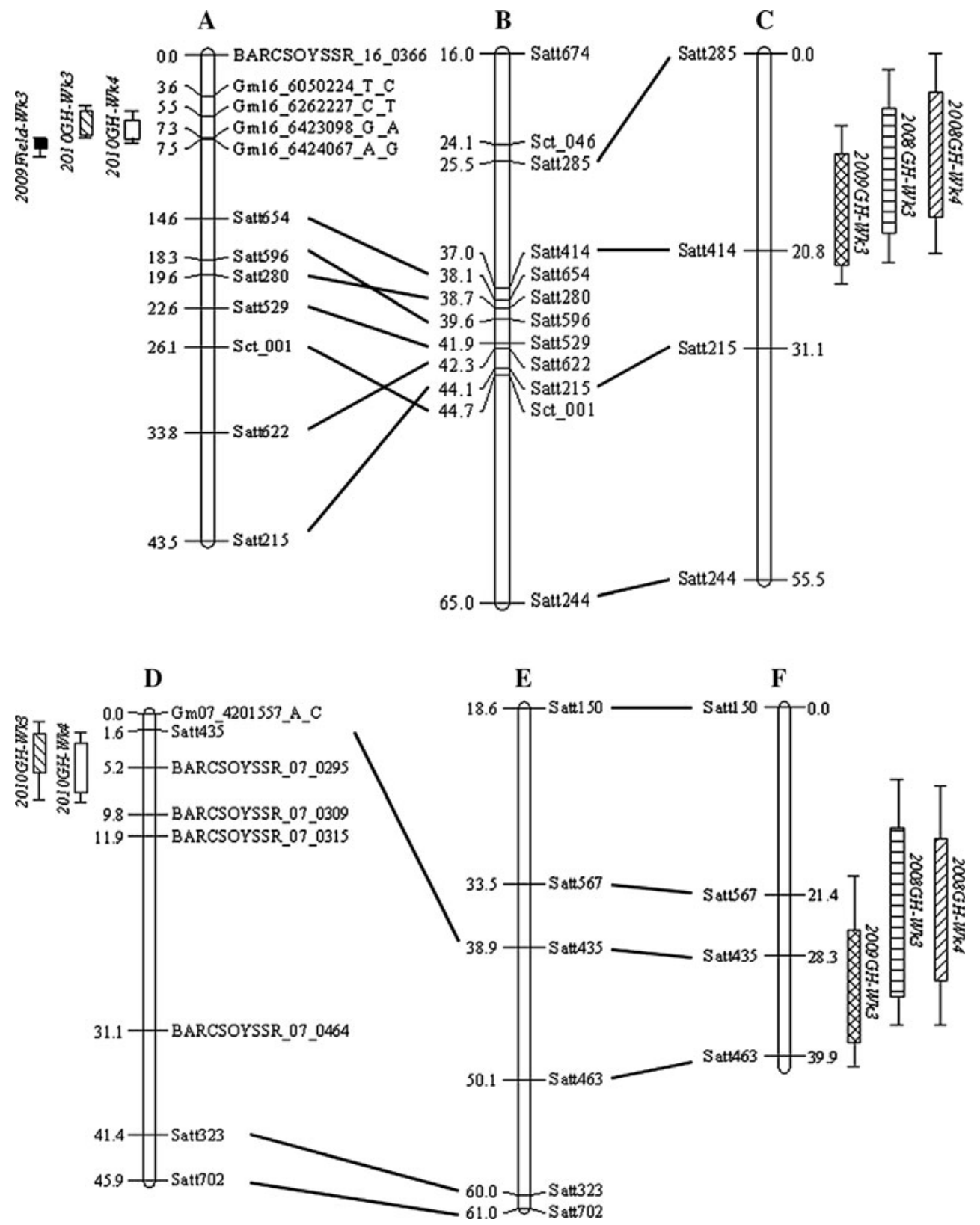

together with their interaction explained $80.4 \%$ of the total phenotypic variation. Results presented from the alternative population confirmed the QTLs found from the mapping population. Since the QTLs from this study were mapped to similar regions as Ragl (Li et al. 2007) and Rag3 (Zhang et al. 2009), we named the locus on chromosome 7 as raglb and the locus on chromosome 16 as rag3, according to the conventions of the Soybean Genetics Committee.

Effect of the combination of QTL alternative alleles

The $\mathrm{F}_{4}$-derived lines from the mapping population were classified based on the SNP and SSR alleles within the
QTL regions identified in E06902. Four distinct genotypes were defined by the presence or absence of the allele from E06902 for those QTL-associated markers on chromosomes 7 and 16 (Table 5). A total of 139 lines were grouped into the defined genotypes and only individual lines with complete and unambiguous genotype data for all loci were included. Mean soybean aphid damage index for all lines within each genotypic group was obtained for each of the trials in 2009 and 2010. In the 2010 greenhouse trial, the presence of E06902 alleles at both raglb and rag 3 gave the lowest aphid damage, while absence of alleles at both QTLs made lines very susceptible (Fig. 3a). The absence of E06902 allele at one QTL (either raglb or rag3) gave intermediate resistance against aphids. However, in the 
Table 2 Summary of QTLs for soybean aphid resistance detected in the main mapping population (IA2070 $\times$ E06902) and alternative population (PI 567598B $\times$ Titan) using the composite interval mapping method

\begin{tabular}{|c|c|c|c|c|c|c|}
\hline \multirow[t]{2}{*}{ Trials } & \multirow[t]{2}{*}{$\mathrm{Chr} / \mathrm{LG}^{\mathrm{a}}$} & \multirow[t]{2}{*}{ Peak pos ${ }^{\mathrm{b}}$} & \multirow[t]{2}{*}{ Flanking markers ${ }^{\mathrm{c}}$} & \multicolumn{3}{|l|}{ QTL $^{d}$} \\
\hline & & & & LOD & $R^{2 \mathrm{e}}$ & $a^{f}$ \\
\hline \multicolumn{7}{|c|}{ IA2070 $\times$ E06902 population } \\
\hline \multicolumn{7}{|l|}{ Field 2009} \\
\hline 3-week rating & $16 / J$ & 7.5 & Gm16_6424067_A_G & 42.5 & 45.8 & -22.1 \\
\hline \multicolumn{7}{|l|}{ Greenhouse 2010} \\
\hline \multirow[t]{2}{*}{ 3-week rating } & $7 / \mathrm{M}$ & 3.6 & Satt435-BARCSOYSSR_07_0295 & 16.6 & 35.5 & -11.2 \\
\hline & $16 / J$ & 5.5 & Gm16_6262227_C_T-Gm16_6423098_G_A & 12.5 & 35.9 & -9.2 \\
\hline \multirow[t]{2}{*}{ 4-week rating } & $7 / \mathrm{M}$ & 5.3 & BARCSOYSSR_07_0295-BARCSOYSSR_07_0309 & 16.7 & 31.2 & -10.3 \\
\hline & $16 / \mathrm{J}$ & 7.3 & Gm16_6423098_G_A-Gm16_6424067_A_G & 15.9 & 30.7 & -9.9 \\
\hline \multirow{2}{*}{\multicolumn{7}{|c|}{$\begin{array}{l}\text { PI 567598B } \times \text { Titan population } \\
\text { Greenhouse } 2008\end{array}$}} \\
\hline & & & & & & \\
\hline \multirow[t]{2}{*}{ 3-week rating } & $7 / \mathrm{M}$ & 23.4 & Satt567-Sattt435 & 2.7 & 14.0 & $6.5^{\mathrm{g}}$ \\
\hline & $16 / J$ & 12.0 & Satt285-Satt414 & 5.0 & 32.6 & 11.5 \\
\hline \multirow[t]{2}{*}{ 4-week rating } & $7 / \mathrm{M}$ & 23.4 & Satt567-Sattt435 & 3.2 & 17.0 & 8.3 \\
\hline & $16 / J$ & 10.0 & Satt285-Satt414 & 4.1 & 28.4 & 12.7 \\
\hline \multicolumn{7}{|l|}{ Greenhouse 2009} \\
\hline \multirow[t]{2}{*}{ 3-week rating } & $7 / \mathrm{M}$ & 30.3 & Satt567-Satt435 & 7.8 & 20.9 & 12.0 \\
\hline & $16 / \mathrm{J}$ & 17.8 & Sct_046-Satt414 & 10.0 & 39.7 & 16.2 \\
\hline \multicolumn{7}{|c|}{${ }^{a}$ Chromosome/Linkage group. The chromosome number and linkage group name are according to the SoyBase (Grant et al. 2010) } \\
\hline \multicolumn{7}{|c|}{${ }^{\mathrm{b}}$ QTL peak position is expressed in $\mathrm{cM}$} \\
\hline \multicolumn{7}{|c|}{ c Markers flanking the peak position } \\
\hline \multicolumn{7}{|c|}{$\begin{array}{l}\text { The LOD thresholds are } 3.89,1.78,2.3,2.4 \text {, and } 5.1 \text { for the field } 2009 \text { rating, the } 3 \text {-week rating in 2010, the } 4 \text {-week rating in } 2010 \text {, the } 3 \text {-week } \\
\text { rating in } 2008 \text { and the } 2009 \text { rating, respectively }\end{array}$} \\
\hline \multicolumn{7}{|c|}{${ }^{\mathrm{e}} R^{2}$, percentage of phenotypic variation explained by a QTL } \\
\hline \multicolumn{7}{|c|}{ f Additive effect: the negative value implies that the IA2070 allele increases the phenotypic value } \\
\hline \multicolumn{7}{|c|}{ g Additive effect: the positive value implies that the PI 567598B allele decreases the phenotypic value } \\
\hline
\end{tabular}

Table 3 Aphid damage index of the $\mathrm{F}_{2}$ derived alternative population and its parents PI 567598B and Titan in the greenhouse trials in 2008 and 2009

\begin{tabular}{|c|c|c|c|c|c|}
\hline \multirow[t]{2}{*}{ Trial } & \multicolumn{2}{|l|}{ Parents $^{\mathrm{a}, \mathrm{b}}$} & \multicolumn{3}{|c|}{$\mathrm{F}_{2}$ population } \\
\hline & PI 567598B & Titan & Mean & Range & SE \\
\hline \multicolumn{6}{|l|}{ Greenhouse 2008} \\
\hline 3-week rating & 17.2 & 70.0 & 53.0 & $12.5 \sim 87.5$ & 19.0 \\
\hline 4-week rating & 25.0 & 87.5 & 70.1 & $25.0 \sim 100.0$ & 21.9 \\
\hline \multicolumn{6}{|l|}{ Greenhouse 2009} \\
\hline 3-week rating & $12.5 \mathrm{a}$ & $80.4 b$ & 41.0 & $12.5 \sim 83.3$ & 20 \\
\hline
\end{tabular}

${ }^{a}$ Within trials and ratings, means followed by the same letters are not significantly different according to Fisher's Protected LSD $(P=0.05)$

${ }^{\mathrm{b}}$ Greenhouse trials in 2008 did not have replicated pots for the parents

2009 field cage trial, the lines without rag3 were as susceptible as those with none of the two QTL alleles from E06902 (Fig. 3b). On the other hand, genotypes containing only rag 3 gave resistant phenotypes that were comparable to the lines that had both resistant alleles. It seems that the QTL on chromosome 7 (raglb) failed to confer resistance in the field trial, while only QTL on chromosome 16 (rag3) conferred resistance. This shows that the QTLs identified in this study confer differential reactions against the soybean aphids in the field and greenhouse trials.

\section{Discussion}

In this study, two QTLs for controlling the aphid resistance in PI 567598B or its derived line were consistently detected in all three years. These two QTLs explained most of the phenotypic variation, indicating that two major genes control the aphid resistance in PI 567598B. This finding is consistent with the conclusion of Mensah et al. (2008), who conducted a genetic study and suggested a two-gene model for the aphid resistance in PI 567598B. Other than soybeans, single recessive genes controlling aphid resistance have been previously reported for wheat (Nkongolo et al. 1991), peanut (Herselman et al. 2004), and corn (So et al. 
Table 4 Summary of QTLs for soybean aphid resistance detected in the main mapping population (IA2070 $\times$ E06902) and alternative population (PI 567598B $\times$ Titan) using the multiple interval mapping method

\begin{tabular}{|c|c|c|c|c|c|c|}
\hline \multirow[t]{2}{*}{ Trials } & \multirow[t]{2}{*}{$\mathrm{Chr} / \mathrm{LG}^{\mathrm{a}}$} & \multirow[t]{2}{*}{ Peak pos. ${ }^{b}$} & \multirow[t]{2}{*}{ Flanking markers ${ }^{\mathrm{c}}$} & \multicolumn{3}{|c|}{ Genetic effect } \\
\hline & & & & $\operatorname{LOD}^{\mathrm{d}}$ & $R^{2 \mathrm{e}}$ & $a^{f}$ \\
\hline \multicolumn{7}{|c|}{ IA2070 $\times$ E06902 population } \\
\hline \multicolumn{7}{|l|}{ Field 2009} \\
\hline 3-week rating & $16 / J$ & 7.5 & Gm16_6424067_A_G & 56.0 & 56.1 & -26.8 \\
\hline \multicolumn{7}{|l|}{ Greenhouse 2010} \\
\hline \multirow[t]{3}{*}{ 3-week rating } & 07/M & 5.3 & BARCSOYSSR_07_0295-BARCSOYSSR_07_0309 & 17.3 & 20.4 & -12.9 \\
\hline & $16 / J$ & 7.5 & Gm16_6424067_A_G & 12.3 & 13.2 & -10.5 \\
\hline & & & Total & & 33.6 & \\
\hline \multirow[t]{4}{*}{ 4-week rating } & 07/M & 6.3 & BARCSOYSSR_07_0295-BARCSOYSSR_07_0309 & 19.9 & 21.2 & -13.0 \\
\hline & $16 / \mathrm{J}$ & 7.5 & Gm16_6424067_A_G & 20.0 & 19.3 & -12.6 \\
\hline & & & Interaction & 3.4 & 1.2 & -4.7 \\
\hline & & & Total & & 41.7 & \\
\hline \multicolumn{7}{|c|}{ PI 567598B $\times$ Titan population } \\
\hline \multicolumn{7}{|l|}{ Greenhouse 2008} \\
\hline \multirow[t]{3}{*}{ 3-week rating } & 07/M & 23.4 & Satt567-Sattt435 & 3.5 & 12.3 & $7.0^{\mathrm{g}}$ \\
\hline & $16 / J$ & 12.0 & Satt285-Satt414 & 5.5 & 37.9 & 13.3 \\
\hline & & & Total & & 50.2 & \\
\hline \multirow[t]{3}{*}{ 4-week rating } & 07/M & 23.4 & Satt567-Sattt435 & 3.4 & 11.7 & 8.0 \\
\hline & $16 / \mathrm{J}$ & 10.0 & Satt285-Satt414 & 4.9 & 30.1 & 13.6 \\
\hline & & & Total & & 41.8 & \\
\hline \multicolumn{7}{|l|}{ Greenhouse 2009} \\
\hline \multirow[t]{4}{*}{ 3-week rating } & 07/M & 31.6 & Satt435 & 8.5 & 12.2 & 9.8 \\
\hline & $16 / J$ & 17.8 & Sct_046-Satt414 & 18.1 & 59.0 & 17.9 \\
\hline & & & Interaction & 6.0 & 9.2 & 8.1 \\
\hline & & & Total & & 80.4 & \\
\hline
\end{tabular}

${ }^{a}$ Chromosome/Linkage group: the chromosome number and linkage group name are according to the SoyBase (Grant et al. 2010)

${ }^{\mathrm{b}}$ QTL peak position is expressed in $\mathrm{cM}$

c Markers flanking the peak position or the marker at the peak position

${ }^{\mathrm{d}}$ Using the same LOD thresholds as in the composite interval mapping method (Table 3)

e $R^{2}$, percentage of phenotypic variation explained by a QTL

f Additive effect: the negative value implies that the IA2070 allele increases the phenotypic value

g Additive effect: the positive value implies that the PI 567598B allele decreases the phenotypic value

Table 5 Genotypic groups of $139 \mathrm{~F}_{4}$-derived lines from the mapping population IA2070 $\times$ E06902 containing alternative alleles of the associated markers on chromosome 7 (raglb) and 16 (rag3)

\begin{tabular}{|c|c|c|c|c|c|c|c|}
\hline \multirow[t]{3}{*}{ Genotype } & \multirow{3}{*}{ No. of lines } & \multicolumn{6}{|c|}{ SSR and SNP Markers } \\
\hline & & \multicolumn{3}{|c|}{ Chromosome 7} & \multicolumn{3}{|l|}{ Chromosome 16} \\
\hline & & Satt435 & $\begin{array}{l}\text { BARCSOYSSR_ } \\
07 \_0295\end{array}$ & $\begin{array}{l}\text { BARCSOYSSR_ } \\
07 \_0309\end{array}$ & $\begin{array}{l}\text { Gm16_6262227 } \\
\text { _C_T }\end{array}$ & Gm16_6423098_G_A & $\begin{array}{l}\text { Gm16_6424067 } \\
\text { _A_G }\end{array}$ \\
\hline rag1b/rag3 & 43 & + & + & + & + & + & + \\
\hline raglb/- & 35 & + & + & + & - & - & - \\
\hline$-/$ rag3 & 40 & - & - & - & + & + & + \\
\hline$-1-$ & 21 & - & - & - & - & - & - \\
\hline
\end{tabular}

+ Implies allele from the E06902 resistant source. - Implies allele from susceptible parent 


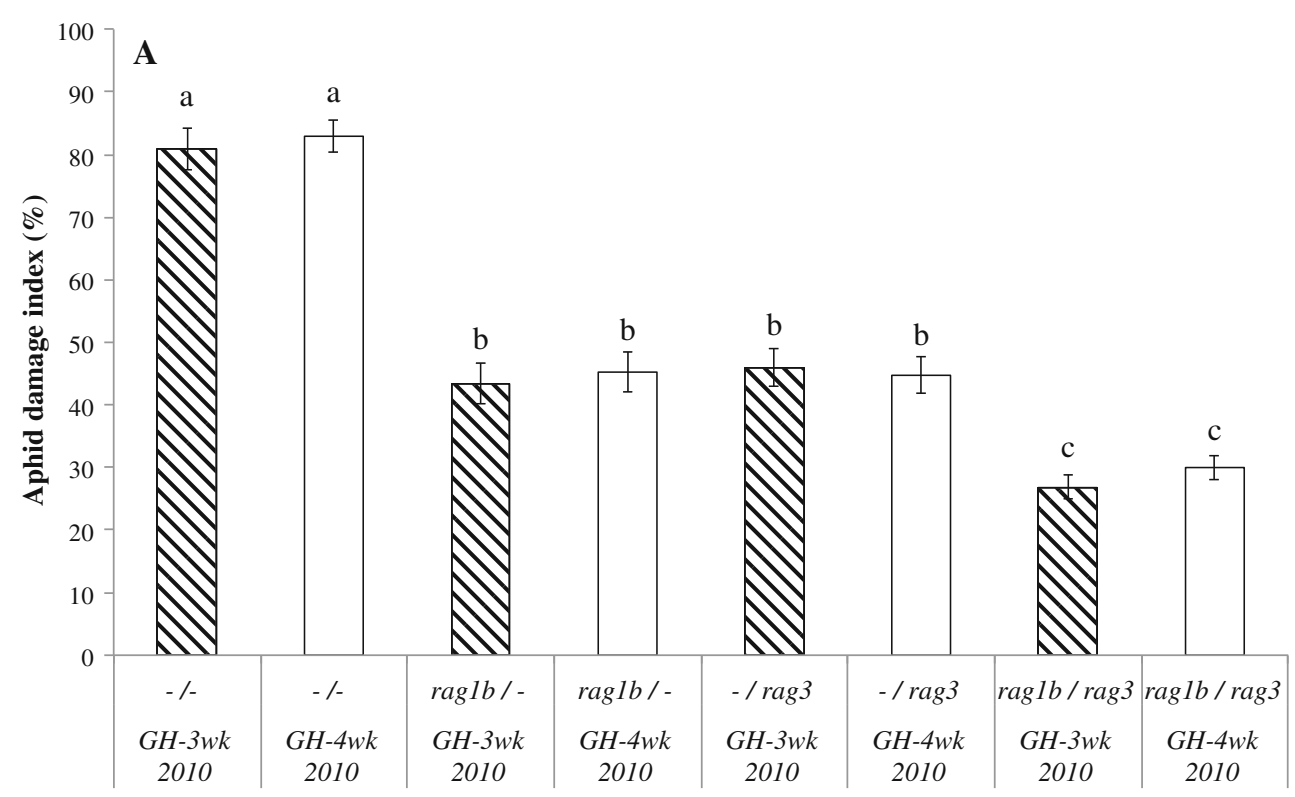

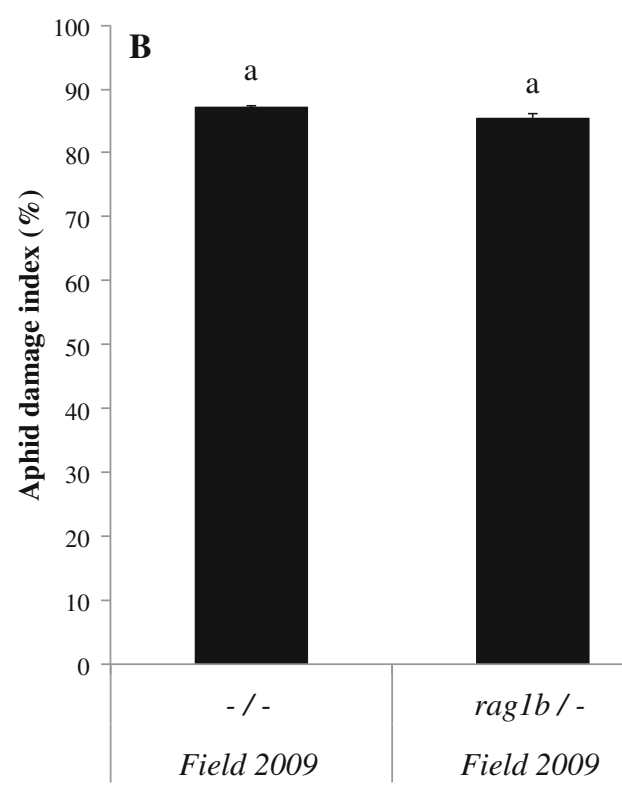

Fig. 3 Mean soybean aphid damage index (\%) for selected lines having alternate alleles within the intervals of Satt435 and BARCSOYSSR_07_0309 (chromosome 7) and with Gm16_6262227_C_T and Gm16_6424067_A_G (chromosome 16) in the mapping population IA2070 $\times$ E06902. a Three-week and 4-week rating in the

2010). The difference or similarity of action between dominant and recessive aphid resistance genes in soybeans remains to be investigated.

The QTLs detected in this study are located in similar genomic regions as Ragl on chromosome 7 (Li et al. 2007, Kim et al. 2010) and Rag3 on chromosome 16 (Zhang et al. 2010). Although the two resistant genes in PI 567598B were considered recessive (Mensah et al. 2008), and Rag1 or Rag3 was considered dominant or co-dominant (Hill et al. 2006a; Zhang et al. 2010), they may still be the same genes as Ragl and Rag3, since the susceptible parent in this study was different from the ones used for characterizing Rag1 and Rag3. It is also possible that the two genes discovered in this study are allelic to Ragl or Rag3, or different genes, but tightly linked to Ragl or Rag3. Ragl in Dowling can be overcome by the Michigan aphids and Rag3 in PI 567543C did not provide antibiosis resistance (Mensah et al. 2005). PI 567598B had a relatively lower DI value than PI 567543C (unpublished data). The better resistance of PI 567598B compared with Dowling and PI 
567543C might be due to one or more of the following factors: (1) the stacking of resistant genes $\mathrm{rag} 1 \mathrm{~b}$ and $\mathrm{rag} 3$; (2) different resistant alleles at raglb or rag3, or both loci conferring better resistance than the alleles in Dowling and PI 567543C; (3) one or two new genes closely linked to Ragl and/or Rag3 have better resistance than Ragl and Rag3. Further investigations, such as fine mapping or gene cloning, might be necessary to elucidate their relationships with Ragl and Rag3.

Different sources of aphids could determine the resistant reaction of a soybean plant containing any of the Rag genes. Our QTL analysis revealed that only rag 3 was detected in the field trial. Zhang et al. (2009) also found that the two resistance genes from PI 567541B were expressed differently in the field and greenhouse trials, which was explained by the different aphid biotypes. In fact, Mensah et al. (2007) found that the Ragl in Dowling was first overcome by the Michigan aphids in 2006. The mixture of aphids used in the 2009 field trial in this study was collected from the Michigan field, which infested Dowling (unpublished data) in that year. This may explain why the QTL on chromosome 7 was not detected in our field trial. However, in the 2010 greenhouse trial, the single aphid clone collected from the field in 2010 was used, and Dowling was resistant to this clone (unpublished data). Consequently, the QTL on chromosome 7 was significant in this trial. This QTL was confirmed with the alternative population infested with the 2002 aphid clone used from the same trial as Mensah et al. (2005), which was not virulent to Ragl and Rag sources. This provides additional information that the QTL on chromosome 7 ( $\mathrm{rag} \mathrm{lb}$ ) may have the same gene action as Ragl. The present study demonstrated that PI 567598B can still be effective to aphids even if one of the resistance genes is overcome, indicating that the presence of both rag $1 \mathrm{~b}$ and $\mathrm{rag} 3$ can confer broader aphid resistance. This supports the hypothesis that stacking more than one aphid resistance gene will provide durable resistance against soybean aphids.

PI 567598B possesses strong and broad resistance to soybean aphids; therefore, it is a promising resistant source for improving aphid resistance in soybean. The localization of the two resistance genes in PI 567598B using molecular markers in this study could be useful to breeders in markerassisted selection for aphid resistance lines.

\section{References}

Beckendorf EA, Catangui MA, Riedell WE (2008) Soybean aphid feeding injury and soybean yield, yield components, and seed composition. Agron J 100:237-246

Churchill GA, Doerge RW (1994) Empirical threshold values for quantitative trait mapping. Genetics 138:963-971

Cooper S (2012) Soybean aphid biotypes: understanding geographic distribution (2008-2012), Monsanto Company. In: Conference presentation for Soybean Breeders' Workshop held February 27-29, 2012, St. Louis, MO, USA

Cregan PB, Quigley CV (1997) Simple sequence repeat DNA marker analysis. In: Caetano-Anolles G, Gresshoff PM (eds) DNA markers: protocols, applications and overviews. Wiley, New York, pp 173-185

Diaz-Montano J, Reese JC, Schapaugh WT, Campbell LR (2006) Characterization of antibiosis and antixenosis to the soybean aphid in several soybean genotypes. J Econ Entomol 999:1884-1889

Diers BW, Isleib TG, Sneller CH, Boyse JF (1999) Titan soybean. Crop Sci 39(5):1534

Grant D, Imsande MI, Shoemaker RC (2010) SoyBase, The USDAARS soybean genome database. http://soybase.agron.iastate.edu

Herselman L, Thwaites R, Kimmins FM et al (2004) Identification and mapping of AFLP markers linked to peanut (Arachis hypogaea L.) resistance to the aphid vector of groundnut rosette disease. Theor Appl Genet 109:1426-1433

Hesler LS, Dashiell KE (2008) Identification and characterization of new sources of resistance to Aphis glycines Matsumura (Hemiptera: Aphididae) in soybean lines. Appl Entomol Zool 43:197-206

Hesler LS, Dashiell KE, Lundgren JG (2007) Characterization of resistance to Aphis glycines in soybean accessions. Euphytica 154:91-94

Hill CB, Li Y, Hartman GL (2004) Resistance to the soybean aphid in soybean germplasm. Crop Sci 44:98-106

Hill CB, Li Y, Hartman GL (2006a) A single dominant gene for resistance to the soybean aphid in the soybean cultivar Dowling. Crop Sci 46:1601-1605

Hill CB, Li Y, Hartman GL (2006b) Soybean aphid resistance in soybean Jackson is controlled by a single dominant gene. Crop Sci 46:1606-1608

Hill CB, Kim KS, Crull L, Diers BW, Hartman GL (2009) Inheritance of resistance to the soybean aphid in soybean PI 200538. Crop Sci 49:1193-1200

Hill CB, Crull L, Herman TK, Voegtlin JD, Hartman GL (2010) A new soybean aphid (Hemiptera: Aphididae) biotype identified. J Econ Entomol 103:509-515

Kang ST, Mian MAR, Hammond RB (2008) Soybean aphid resistance in PI 243540 is controlled by a single dominant Gene. Crop Sci 48:1744-1748

Kim K, Hill CB, Hartman GL, Mian MR, Diers BW (2008) Discovery of soybean aphid biotypes. Crop Sci 48:923-928

Kim K, Bellendir S, Hudson KA, Hill CB, Hartman GL, Hyten DL, Hudson ME, Diers BW (2010) Fine mapping the soybean aphid resistance gene Rag1 in soybean. Theor Appl Genet 120:1063-1071

Kisha T, Sneller CH, Diers BW (1997) Relationship between genetic distance among parents and genetic variance in populations of soybean. Crop Sci 37:1317-1325

Li Y, Hill CB, Carlson SR, Diers BW, Hartman GL (2007) Soybean aphid resistance genes in the soybean cultivars Dowling and Jackson map to linkage group M. Mol Breed 19:25-34

Liu XM, Smith CM, Friebe BR, Gill BS (2005) Molecular mapping and allelic relationships of Russian wheat aphid-resistance genes. Crop Sci 45:2273

Mensah C, Difonzo C, Nelson RL, Wang D (2005) Resistance to soybean aphid in early maturing soybean germplasm. Crop Sci 45:2228-2233

Mensah C, DiFonzo C, Wang D (2007) A case for the presence of soybean aphid biotypes in Michigan. In: 2007 annual meeting abstracts [CD-ROM]. ASA, CSSA, and SSSA, Madison, WI

Mensah C, Difonzo C, Wang D (2008) Inheritance of soybean aphid resistance in PI 567541B and PI 567598B. Crop Sci 48:1759-1763 
Mian MAR, Hammond RB, St Martin SK (2008a) New plant introductions with resistance to the soybean aphid. Crop Sci 48:1055-1061

Mian MAR, Kang ST, Beil SE, Hammond RB (2008b) Genetic linkage mapping of the soybean aphid resistance gene in PI 243540. Theor Appl Genet 117:955-962

Michel AP, Zhang W, Jung JK, Kang ST, Mian MAR (2009) Population genetic structure of Aphis glycines. Environ Entomol 38:1301-1311

Michelmore RW, Paran J, Kesseli RV (1991) Identification of markers linked to disease resistance genes by bulked segregant analysis: a rapid method to detect markers in specific genomic regions by using segregating populations. Proc Natl Acad Sci 88:9828-9832

Mornhinweg DW, Porter DR, Webster JA (2002) Inheritance of russian wheat aphid resistance in spring barley germplasm line STARS-9577B. Crop Sci 42:1891

Nkongolo KK, Quick JS, Limin AE, Fowler DB (1991) Sources and inheritance of resistance to Russian wheat aphid in Triticum species amphiploids and Triticum tauschii. Can J Plant Sci 71:703-708

Painter RH (1951) Insect Resistance in Crop Plants. Macmillan Publishing Co, New York

Pascal T, Pfeiffer F, Kervella J et al (2002) Inheritance of green peach aphid resistance in the peach cultivar "Rubira". Plant Breeding 121:459-461

Pathak RS (1988) Genetics of resistance to aphid in cowpea. Crop Sci 28:474-476

R Development Core Team (2008) R: A language and environment for statistical computing. R Foundation for Statistical Computing, Vienna

So Y-S, Ji HC, Brewbaker JL (2010) Resistance to corn leaf aphid (Rhopalosiphum maidis Fitch) in tropical corn (Zea mays L.). Euphytica 172:373-381
Song QJ, Marek LF, Shoemaker RC, Lark KG, Concibido VC, Delannay X, Specht JE, Cregan PB (2004) A new integrated genetic linkage map of the soybean. Theor Appl Genet 109:122-128

Song Q, Jia G, Zhu Y, Grant D, Nelson R, Hwang E, Hyten D, Cregan $P$ (2010) Abundance of SSR motifs and development of candidate polymorphic SSR markers (BARCSOYSSR_1.0) in soybean. Crop Sci 50:1950-1960

Song Q, Hyten DL, Jia G, Quigley CV, Fickus EW, Nelson RL, Cregan PB (2013) Development and evaluation of SoySNP50K, a high-density genotyping array for soybean. PLoS ONE 8(1):e54985

Van Ooijen JW (2006) JoinMap ${ }^{\circledR} 4$, Software for the calculation of genetic linkage maps in experimental populations. Kyazma B.V., Wageningen, Netherlands

Voorrips RE (2002) MapChart: Software for the graphical presentation of linkage maps and QTLs. J Heredity 93:77-78

Wang D, Shi J, Carlson SR, Cregan PB, Ward RW, Diers BW (2003) A low-cost and high-throughput system for high-resolution genotyping with microsatellite DNA markers. Crop Sci 43:1828-1832

Wang S, Basten CJ, Zeng ZB (2008) Windows QTL Cartographer 2.5. Department of Statistic, North Carolina State Univ, Raleigh. http://statgen.ncsu.edu/qtlcart/WQTLCart.htm

Wu Z, Schenk-Hamlin D, Zhan W, Ragsdale DW, Heimpel GE (2004) The soybean aphid in China: a historical review. Ann Entomol Soc Am 97:209-218

Zeng ZB (1994) Precision mapping of quantitative trait loci. Genetics 136:1457-1468

Zhang G, Gu C, Wang D (2009) Molecular mapping of soybean aphid resistance in PI 567541B. Theor Appl Genet 118:473-482

Zhang G, Gu C, Wang D (2010) A novel locus for soybean aphid resistance. Theor Appl Genet 120:1183-1191 